\title{
Developmental and Physiologic Changes in Cerebral Blood Flow Velocity
}

\author{
ISAAC HORIUCHI. SATOSHI SANADA. AND SHUNSUKE OHTAHARA
}

Department of Child Neurology, Okayama University Medical School, Shikatacho, Okayama 70), Japan

\begin{abstract}
Developmental change of mean blood flow velocity (MBFV) and resistance index of the basilar artery (BA), as well as the changes in MBFV of the BA and the middle cerebral artery (MCA) during sleep and hyperventilation, were studied using transcranial Doppler sonography in healthy Japanese subjects. The MBFV of the BA increased with age from infancy through early childhood, reaching the maximum $(64.4 \pm 2.6 \mathrm{~cm} / \mathrm{s})$ at the age of $5 \mathrm{y}$, and then gradually decreased. MBFV ratio of MCA to $B A$ was almost stable between 1.57 to 1.64 in all age groups. The resistance index of the $B A$ showed a maximum value in infants, decreased in 1 - to 2-y-olds, and remained constant thereafter. The MBFV of both the MCA and BA were lower during non-rapid eye movement sleep than during wakefulness, whereas during rapid eye movement sleep they showed almost the same value as during wakefulness. They were also decreased during hyperventilation. At an expiratory $\mathrm{CO}_{2}$ level of $25 \mathrm{~mm} \mathrm{Hg}(33.33 \mathrm{kPa})$, the average decrease in MBFV in children $(n=10)$ was -50.1 $\pm 3.9 \%$ in the $\mathrm{BA}$, and $-46.2 \pm 7.4 \%$ in the MCA, significantly $(p<0.05)$ more marked than that in adults $(n=10)(-41.5 \pm 5.9 \%$ and $-37.9 \pm 4.2 \%$, respectively $)$. Transcranial Doppler sonography is a noninvasive method that has a potentially wide range of applications in pediatric neurology. (Pediatr Res 34: 385-388, 1993)
\end{abstract}

\section{Abbreviations}

BFV, blood flow velocity

MBFV, mean blood flow velocity

$R I$, resistance index

MCA, middle cerebral artery

BA, basilar artery

$\mathrm{PECO}_{2}$, expiratory carbon dioxide tension

$\mathrm{PaCO}_{2}$, arterial carbon dioxide tension

ANOVA, analysis of variance

RE. II, rapid eye movement

CBF, cerebral blood flow

Transcranial Doppler, introduced by Aaslid et al. (1) in 1982, is a noninvasive method that can provide detailed information regarding cerebral blood flow. Because of these advantages, it can be applied in clinical measurement, repeatedly or continuously. Ic offers the additional advantage of real-time visualization of the blood flow.

Using this method, Murakami (2), found that developmental changes in MBFV of the MCA showed a maximum velocity at the age of $4 \mathrm{y}$, and that the RI of the MCA showed the most remarkable decrease at age 6 mo.

Received October 8, 1992; accepted May 14, 1993.

Correspondence and reprint requests: I. Horiuchi, M.D., Department of Child Neurology, Okayama University Medical School, Shikatacho, Okayama 700, Japan.
However, regarding the vertebral-basilar arterial system, especially developmental change of the MBFV of the BA, there has been only one reported study, by Bode and Wais (3), that did not include subjects in the $1 \mathrm{st}$ year of life. We therefore examined developmental changes of the MBFV of the BA from the 1st year of life through adulthood in an attempt to establish standard reference data. We also examined the changes in MBFV under various physiologic conditions to contribute to the diagnosis of cerebral vascular disease.

\section{SUBJECTS AND METHODS}

The subjects were 150 neurologically normal Japanese children and adults ( 75 males and 75 females) who had no history of any hematologic or cardiovascular diseases. Informed consents were obtained from all subjects. They were classified into nine age groups as shown in Table 1 . In 72 of them, both BA and MCA were examined, and then the MBFV ratio of MCA to BA was investigated. A transcranial Doppler (EME TC2-64, Eden Medizinische Elektronik $\mathrm{GmbH}$, Ueberlingen, Germany) was used for the measurement of the MBFV of the BA and MCA. For the detection of the MBFV of the BA, a 2-MHz probe was placed on the area between the 2 nd cervical vertebra and occipital node. Then, ultrasound was applied to the BA, and reverse flow was recorded. For the detection of MBFV of the MCA, flow was detected using a probe placed on the right temporal area anterior to the auricle.

RI was calculated according to the following formula (4): RI $=($ systolic flow velocity - diastolic flow velocity $) /$ systolic flow velocity.

The EME TC2-64 blood flowmeter, which operates on the pulsed Doppler principle, can measure BFV at depths ranging from 25 to $150 \mathrm{~mm}$, at $5-\mathrm{mm}$ intervals. In this study, the depth at which the BFV of the BA could be detected ranged from 35 to $90 \mathrm{~mm}$, and each subject showed a specific range. In subjects who showed many depths at which maximum pulsed flow signal could be detected, the middle point was selected as the optimal depth.

We studied the relationship between head circumference and optimal pulsed signal depth, and there was a significant relationship between head circumference and optimal pulsed signal depth $(y=1.606 x-22.78, r=0.751)$.

To evaluate changes in the MBFV of the MCA and BA during natural sleep, all-night sleep polygraph (EEG, electro-oculogram, geniohyoid muscle electromyogram, pneumogram, and ECG) recordings were obtained in 10 subjects (six males and four females) ranging in age from 10 to $32 \mathrm{y}$, and the MBFV of the $\mathrm{BA}$ and MCA were recorded during each sleep stage estimated according to the Association for the Psychophysiological Study of Sleep criteria (5). MBFV showed fluctuation when respiration became irregular. Therefore, MBFV were measured during the stable MBFV period, i.e. at least 5 min later when respiration is estimated regular.

Hypocapnia was induced by hyperventilation in 10 children (five males and five females), ranging in age from 6 to $15 \mathrm{y}$, and 
Table 1. Subjects and $M C A / B A$ ratio*

\begin{tabular}{cccc}
\hline Age & BA & BA and MCA & $\begin{array}{c}\text { MCA/BA } \\
\text { ratio (SD) }\end{array}$ \\
\hline $0-4 \mathrm{mo}$ & $10(\mathrm{M} 5, \mathrm{F5})$ & $5(\mathrm{M} 3, \mathrm{~F} 2)$ & $1.60(0.08)$ \\
$4-8 \mathrm{mo}$ & $12(\mathrm{M} 6, \mathrm{~F} 6)$ & $7(\mathrm{M} 2, \mathrm{F5})$ & $1.62(0.11)$ \\
$8-12 \mathrm{mo}$ & $10(\mathrm{M} 5, \mathrm{~F} 5)$ & $5(\mathrm{M} 3, \mathrm{~F} 2)$ & $1.64(0.13)$ \\
$1-4 \mathrm{y}$ & $15(\mathrm{M} 8, \mathrm{~F} 7)$ & $9(\mathrm{M} 2, \mathrm{~F} 7)$ & $1.63(0.11)$ \\
$4-7 \mathrm{y}$ & $19(\mathrm{M} 10, \mathrm{F9})$ & $8(\mathrm{M} 4, \mathrm{~F} 4)$ & $1.59(0.13)$ \\
$7-10 \mathrm{y}$ & $17(\mathrm{M} 8, \mathrm{F9})$ & $7(\mathrm{M} 4, \mathrm{~F} 3)$ & $1.57(0.14)$ \\
$10-15 \mathrm{y}$ & $17(\mathrm{M} 10, \mathrm{~F} 7)$ & $6(\mathrm{M} 3, \mathrm{~F} 3)$ & $1.62(0.17)$ \\
$15-20 \mathrm{y}$ & $23(\mathrm{M} 9, \mathrm{~F} 14)$ & $10(\mathrm{M} 4, \mathrm{~F} 6)$ & $1.64(0.08)$ \\
$20-30 \mathrm{y}$ & $27(\mathrm{M} 14, \mathrm{~F} 13)$ & $15(\mathrm{M} 8, \mathrm{~F} 7)$ & $1.57(0.12)$ \\
Total & $150(\mathrm{M} 75, \mathrm{~F} 75)$ & $72(\mathrm{M} 33, \mathrm{~F} 39)$ & \\
\hline
\end{tabular}

* M, male; F, female.

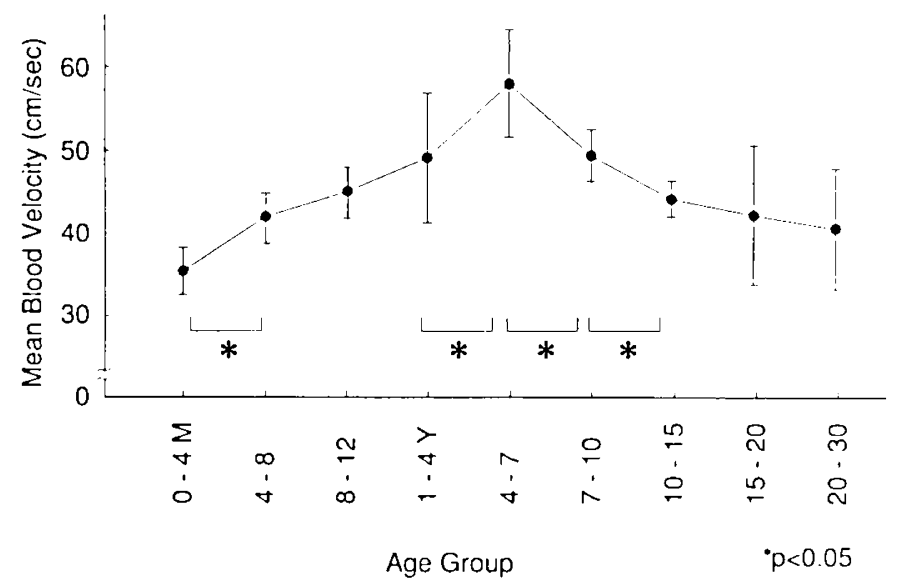

Fig. 1. Developmental change of the MBFV of the BA.

10 adults (five males and five females), ranging in age from 18 to $32 \mathrm{y}$. $\mathrm{PECO}_{2}$, which is considered to be almost the same as $\mathrm{PaCO}_{2}$, was measured with a Respina $1 \mathrm{H} 26$ (NEC-Sanei, Tokyo, Japan). The subjects were instructed to breathe 20 times $/ \mathrm{min}$, as indicated by a metronome, so that the mean $\mathrm{PECO}_{2}$ level was reduced from $40 \mathrm{~mm} \mathrm{Hg}(53.33 \mathrm{kPa})$ to $25 \mathrm{~mm} \mathrm{Hg}(33.33 \mathrm{kPa})$ in $30 \mathrm{~s}$. When the $\mathrm{PECO}_{2}$ level had stabilized at $25 \mathrm{~mm} \mathrm{Hg}(33.33$ $\mathrm{kPa}$ ) for $5 \mathrm{~s}, \mathrm{MBFV}$ measurement was begun. RI was calculated afterwards.

Statistical analyses of these results were performed by ANOVA and $t$ test.

\section{RESULTS}

Developmental change in $M B F V$ of $B A$. The MBFV of the BA measured at the optimal pulsed signal depth for each age group is shown in Figure 1. MBFV was $35.5 \pm 2.9 \mathrm{~cm} / \mathrm{s}$ in subjects 0 to $4 \mathrm{mo}$ of age, and increased with age thereafter until reaching its maximum value in the 4- to $7-y$ age group. To be more precise, we examined this group by year, and at the age of $5 \mathrm{y}$, it showed maximum velocity. MBFV then gradually decreased with age. ANOVA revealed a significant relationship between age group and the MBFV of the BA, and $t$ test of each consecutive age group revealed significant differences among the 0 to 4 and 4 to $8 \mathrm{mo}, 1$ to 4 and 4 to $7 \mathrm{y}$, and 4 to 7 and 7 to $10 \mathrm{y}$ age groups, as indicated by asterisks in Figure 1. There was no significant difference in MBFV value of the BA between males and females within each age group.

$\mathrm{MCA} / \mathrm{BA}$ ratio was almost stable between 1.57 and 1.64 in all age groups as shown in Table 1 .

Developmental change in RI. As shown in Figure 2, RI showed a fairly constant value of $0.57-0.58$ during the 1 st year of life. RI then decreased in 1- to 4-y-olds, and was constant thereafter. To determine the critical age of decrease in RI, we examined the

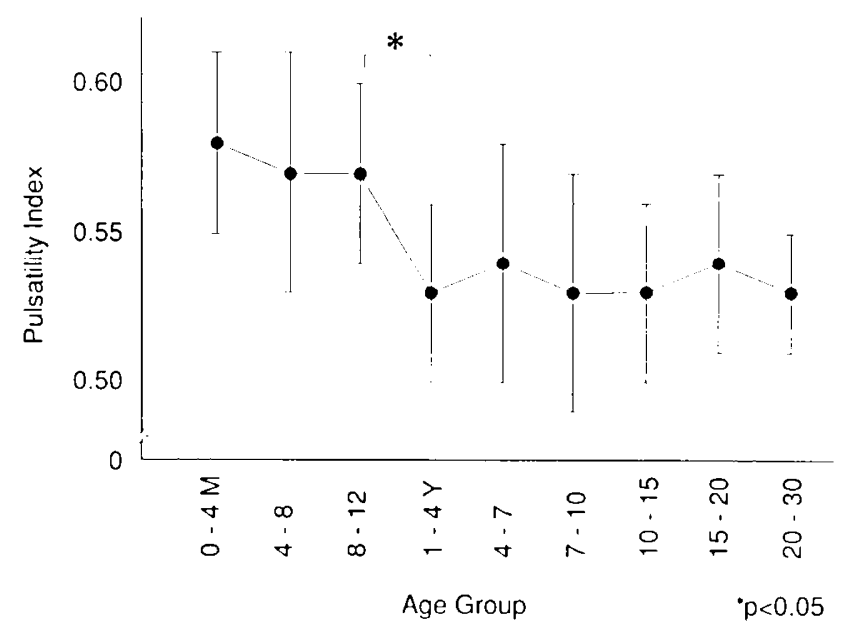

Fig. 2. Developmental change of the RI of the BA.

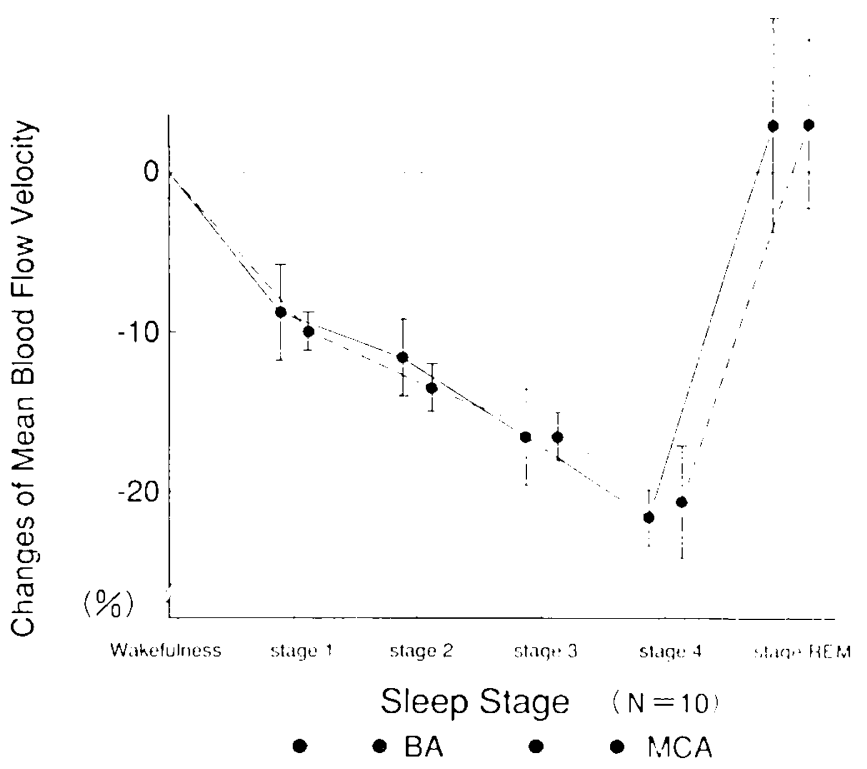

Fig. 3. Changes in the MBFV of the $B A$ and $M C A$ during slec $p$ stages.

RI values of 1- to 4-y-olds; RI was found to show the most marked decrease at the age of $1 \mathrm{y}$. There was a significant relationship between age and $R I$ value (ANOVA).

Changes in $M B F V$ of $B A$ and $M C A$ during sle' $p$. The changes in MBFV of the BA and MCA during stages of natural sleep in comparison with mean value during wakefulness are shown in Figure 3. MBFV during non-REM sleep were lower than inose during wakefulness. There were significant relationships between the MBFV of the BA and MCA and stages of non-R.EM sleep (ANOVA). On the other hand, there was no significant difference between REM-period and wakeful MBFV in the BA and MCA.

During each REM period, which lasted 10 to $30 \mathrm{~min}$, one to three episodes of apnea of 5 to $10 \mathrm{~s}$ duration each werc observed. During these episodes, MBFV were increased by 10 to $30 \%$ compared with those during the wakeful state; the MBFV during these periods were excluded from the estimation of MBFV during REM sleep. Concerning the difference between MBFV of the BA and the MCA during natural sleep, they showed no significant difference in change.

Changes in $M B F V$ of $B A$ and $M C A$ during hypenentilation. The BFV of the BA and MCA decreased with hyperventilation (Fig. 4). The average decreases in the MBFV of the BA and MCA in children were significantly $(p<0.05)$ greater than those in adults. There was no significant difference between the groups in relative response to $\mathrm{CO}_{2}$ in the $\mathrm{BA}$ and $\mathrm{MCA}$.

The RI of the BA and MCA increased significantly during 


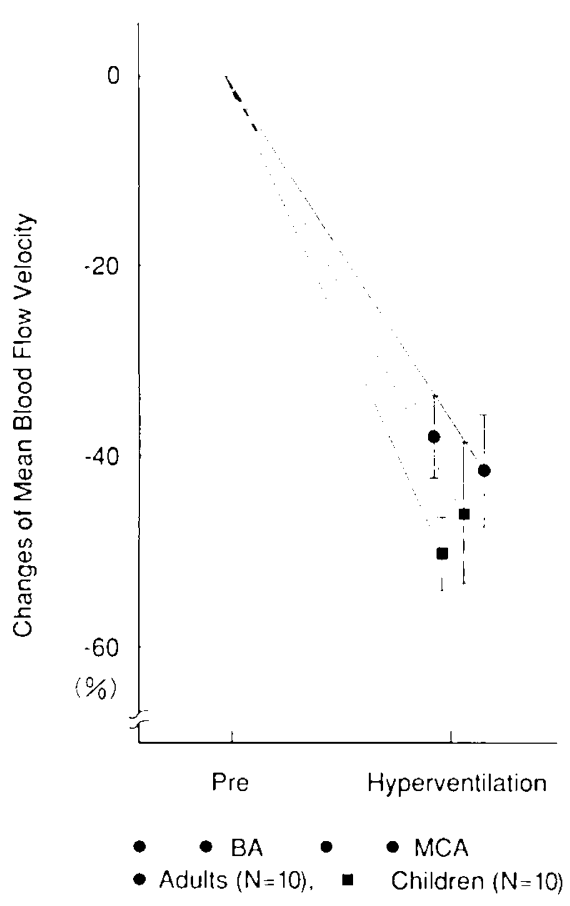

Fig. 4. Changes in the MBFV of the BA and MCA during hyperventilation.

hyperventilation. There was no significant difference between children and adults or between the BA and MCA in change in $\mathrm{RI}$. There was no significant difference between males and females in MBFV values or RI values during hyperventilation.

\section{DISCUSSION}

Our results clarified that $\mathrm{MBFV}$ of the BA shows developmental change with a single peak at age $5 \mathrm{y}$. Kety (6) reviewed the literature regarding $C B F$ volume measured by the $\mathrm{N}_{2} \mathrm{O}$ method and concluded that $C B F$ volume shows maximum value at the age of $5 \mathrm{y}$. This conclusion is compatible with the results obiained by Chiron et al. (7) by single photon emission computerized tomography using ${ }^{133} \mathrm{Xe}$, which showed the highest value between the ages of 4 and $8 \mathrm{y}$. Chugani et al. (8), using positron emission tomography, also found that cerebral glucose metabolism shows a peak between the ages of 3 and $9 \mathrm{y}$ and hypothesized that the development of myelination and maintenance of membrane potentials of developing synapses and dendritic processes in this age group requires active glucose metabolism. These extensive maturational changes apparently require ample supplies of blood.

In our study, a significant decrease in the RI of the BA was obierved between the ages of 1 and $2 \mathrm{y}$, which is later than the decrease in the RI of MCA reported at 6 mo by Murakami (2). Accorcingly, the age period at which RI reaches a constant value can be presumed to vary for different vascular systems. RI is considered to reflect cerebrovascular resistance, and Bode and Wais (3) speculated that increase of capillary density in the brain might be the reason for the decrease in RI observed during infancy. In addition, Otto and Liese (9) found that developmental change of the percentage volume of the cerebellar cortex and occipital pole, which are irrigated by the BA, increased later than that of MCA-irrigated regions. These topographical differences in brain capillary development are presumed to account for the diffcrent ages during which stabilization of $\mathrm{RI}$ in different vascula: systems takes place.

A few studies of CBF during sleep using various methods have been reported (10-13), and cerebral hemodynamic changes during non-REM sleep have also been studied (14) using transcranial Doppler. Consistent with our results, a gradual decrease in $\mathrm{CBF}$ during sleep stages 1 to 4 of non-REM sleep has been reported (12-14). Concerning the CBF during REM sleep, Townsend $c t$ al. (13) found an $8 \%$ increase in cortical CBF compared with that during the wakeful state using the ${ }^{133} \mathrm{Xe}$ inhalation regional $\mathrm{CBF}$ measurement method. In our study, the MBFV of both the $\mathrm{BA}$ and MCA during REM sleep were higher than those of nonREM sleep, but, compared with those during the wakeful state. the difference was about $3 \%$, which was not significant. The specificity of the ${ }^{133} \mathrm{Xe}$ inhalation regional $\mathrm{CBF}$ method that predominantly reflects the $\mathrm{CBF}$ of the cortical surface rather than the deeper cortex might be one factor in the difference between our results and those of Townsend et al.

Several studies of the changes in cerebral hemodynamics during hyperventilation have been reported (15-19), but changes in the MBFV of the BA in childhood have not yet been reported. Markwalder et al. (17) reported that decrease in the MBFV of the MCA was in accordance with the decrease of $\mathrm{PECO}_{2}$, and that response to hyperventilation decreases with age. The findings in our study that the MBFV of the MCA decreased with the decrease of $\mathrm{PECO}_{2}$ and that the rate of decrease in children was greater than that in adults corresponds well with the results reported Markwalder et al.

In addition, we found that the response of the MBFV of the $\mathrm{BA}$ to change in $\mathrm{PECO}_{2}$ is also more marked in children than in adults. The rate of change in MBFV found in this study (2.5$3.3 \%$ per $1 \mathrm{~mm} \mathrm{Hg}$, i.e. $1.33 \mathrm{kPa}$ ) is smaller than that reported by Lassen (20), i.e. a decrease of CBF volume of $4 \%$ as $\mathrm{PaCO}_{2}$ decreases $1 \mathrm{~mm} \mathrm{Hg}(1.33 \mathrm{kPa})$, in a physiologic state. Huber and Handa (21) demonstrated using angiography that the diameters of the main cerebral arteries are constant regardless of $\mathrm{PaCO}_{2}$ changes. Taylor et al. (22), however, suggested on the basis of the study in lamb that an enlargement in mean vessel diameter as $\mathrm{CBF}$ increases causes underestimation of the degree of change in MBFV by Doppler measurement in comparison with that of $\mathrm{CBF}$ volume by the radiolabeled microsphere technique. The smaller degree of change in MBFV in our study than in that by Lassen supports this suggestion (22).

Transcranial Doppler has been clinically applied for perinatal brain damage, hydrocephalus (23), and brain death (24). In recent years, the examination of cerebrovascular response to the administration of $\mathrm{CO}_{2}$ and $\mathrm{O}_{2}$ and to hyperventilation have been considered useful in the diagnosis of cerebrovascular disorders, such as arteriovenous malformation (25), moyamoya disease (26), and stenosis and occlusions (27) of main cerebral arteries. Meanwhile, in our study, the MCA/BA ratio was stable through infancy to adulthood; therefore, this ratio is considered useful for estimation of the distribution of intracranial hemodynamics irrespective of age. The method used in this study is noninvasive, and can therefore be expected to be useful in a wide range of clinical applications in the field of pediatrics and child neurology.

\section{REFERENCES}

1. Aaslid R, Markwalder TM, Nornes H 1982 Noninvasive transcranial Doppler ultrasound recordings of flow velocity in basal cerebral arteries. J Neurosurg 57:769-774

2. Murakami N 1988 A study on intracranial hemodynamics by Doppler ultrasound (in Japanese). No To Hattatsu 20:279-287

3. Bode H, Wais U 1988 Age dependence of flow velocities in basal cerebral arteries. Arch Dis Child 63:606-611

4. Pourcelot L 1975 Applications cliniques de l'examen Doppler transcutane. In: Peronneau P (ed) Velocimetri Ultrasonore Doppler. INSERM, Paris, pp 213-214

5. Rechtschaffen A, Kales A 1968 A Manual of Standardized Terminology, Techniques and Scoring System for Sleep Stages of Human Subjects. Public Health Service, US Government Printing Office, Washington, DC

6. Kety SS 1956 Human cerebral blood flow and oxygen consumption as related to aging. J Chronic Dis 3:478-486

7. Chiron C, Raynaud C, Mazière B, Zibovicius M. Laflamme L, Masure MC Dulac O. Bourguignon M. Syrota A 1992 Changes in regional cerebral blood flow during brain maturation in children and adolescents. I Nucl Med 33:696-703

8. Chugani HT, Phelps ME, Mazziotta JC 1987 Positron emission tomography study of human brain functional development. Ann Neurol 22:487-497

9. Otto KB, Liese W 1970 Die Kapillarisierung verschiedener Teile des men- 
schlichen Gehirns in der Fetalperiode und in den ersten Lebensjahren (in German). Acta Anat 77:25-36

10. Mangold R, Sokoloff L, Conner E, Kleinermann J, Therman POG, Kety SS 1955 The effects of sleep and lack of sleep on the cerebral circulation and metabolism of normal young men. J Clin Invest 34:1092-1100

11. Meyer JS, Hayman LA, Amano T, Nakajima S, Shaw T, Lauzon P, Derman S, Karacan I, Harati Y 1981 Mapping local blood flow of human brain by CT scanning during stable xenon inhalation. Stroke 12:426-436

12. Sakai F, Meyer JS, Karacan I, Derman S, Yamamoto M 1980 Normal human sleep: regional cerebral hemodynamics. Ann Neurol 7:471-478

13. Townsend RE, Prinz PN, Obrist WD 1973 Human cerebral blood fow during sleep and waking. J Appl Physiol 35:620-625

14. Fischer AQ, Taormina MA, Akhtar B, Chaudhary BA 1991 The effect of sleep on intracranial hemodynamics: a transcranial Doppler study. J Child Neurol $6: 155-158$

15. Kety SS, Schmidt CF 1948 Effects of altered arterial tensions of carbon dioxide and oxygen on cerebral blood flow and cerebral oxygen consumption of normal young men. J Clin Invest 27:484-492

16. Yamaguchi F, Meyer JS, Sakai F, Yamamoto M 1979 Normal human aging and cerebral vasoconstrictive responses to hypocapnia. J Neurol Sci 44:8794

17. Markwalder T-M, Grolimund P, Seiler RW, Roth F, Aaslid R 1984 Dependency of blood flow velocity in the middle cerebral artery on end-tidal carbon dioxide partial pressure: a transcranial ultrasound Doppler study. J Cereb Blood Flow Metab 4:368-372

18. Kraaier V, Van Huffelen AC, Wieneke GH 1988 Changes in quantitative EEG and blood flow velocity due to standardized hyperventilation: a model of transient ischaemia in young human subjects. Electroenceph Clin Neurophysiol 70:377-387

19. Yoneda S. Handa N, Ogawa S. Matsumoto M, Kimura K, Kamada T 1987 Carbon dioxide reactivity of the human basilar artery using a transcranial Doppler technique. J Cardiovasc Ultrason 6:255-258

20. Lassen NA 1974 Control of cerebral circulation in health and disease. Circ Res 34:749-760

21. Huber P, Handa J 1967 Effect of contrast material, hypercapnia, hyperventilation, hypertonic glucose and papaverine on the diameter of the cerebral arteries: angiographic determination in man. Invest Radiol 2:17-32

22. Taylor GA, Short BL, Walker LK. Traystman RJ 1990 Intracranial blood flow: quantification with duplex Doppler and color Doppler flow US. Radiology 176:231-236

23. Norelle A, Fischer AQ. Flannery AM 1989 Transcranial Doppler: a noninvasive method to monitor hydrocephalus. J Child Neurol 4:S87-S90

24. Petty GW, Mohr JP. Pedley TA. Tatemichi TK, Lennihan L, Duterte DI, Sacco RL 1990 The role of transcranial Doppler in confirming brain death: sensitivity, specificity, and suggestions for performance and interpretation. Neurology 40:300-303

25. Lindegaard K, Grolimund P, Aaslid R, Nornes H 1986 Evaluation of cerebral AVMs using transcranial Doppler ultrasound. J Neurosurg 65:335-344

26. Fujimoto T, Fukushima $Y 1992$ Evaluation of intracranial hemodynamics and vascular reactivity in moyamoya disease by transcranial Doppler ultrasound. In: Oka M, von Reutern GM. Furuhata H, Kodaira K (eds) Recent Advances in: Neurosonology. Elesevier Science Publishers BV. Amsterdam, pp 83-86

27. Ringelstein EB, Sievers C, Ecker S, Schneider PA, Otis SM 1988 Noninvasive assessment of $\mathrm{CO}_{2}$-induced cerebral vasomotor response in normal individ uals and patients with internal carotid artery occlusions. Stroke 16:963-969 